\title{
Fitossociologia de uma floresta inundável monodominante de Vochysia divergens Pohl (Vochysiaceae), no Pantanal Norte, MT, Brasil
}

\author{
Julia Arieira ${ }^{1,2}$ e Cátia Nunes da Cunha ${ }^{1}$
}

Recebido em 4/07/2005. Aceito em 9/01/2006

\begin{abstract}
RESUMO - (Fitossociologia de uma floresta inundável monodominante de Vochysia divergens Pohl (Vochysiaceae), no Pantanal Norte, MT, Brasil). Cambarazais são formações florestais monodominantes de Vochysia divergens Pohl. O rápido espalhamento de cambarazais em campos sazonalmente inundados no Pantanal tem sido considerado um efeito de mudanças climáticas ocorridas em ciclos plurianuais. Realizado na RPPN SESC Pantanal, Barão de Melgaço, Mato Grosso (Brasil), o presente estudo, inserido no Programa de Pesquisas Ecológicas de Longa Duração (PELD), teve por objetivo analisar a estrutura do cambarazal presente na Reserva, ao longo de um gradiente hidro-topográfico. Os dados fitossociológicos foram coletados em quatro áreas de 1 ha $(100 \times 100 \mathrm{~m})$. Todos os indivíduos com CAP (Circunferência à Altura do Peito) $\geq 5 \mathrm{~cm}$ foram identificados, medidos seus perímetros e estimadas suas alturas. Um total de 3.149 indivíduos foi amostrado nos quatro hectares e 83 espécies foram identificadas. A diversidade de espécies ao longo do gradiente mostrou relação inversa com a altura da lâmina de água da inundação. A parcela com menor nível de inundação (P1) obteve o maior índice de diversidade de espécies dentre as parcelas $\left(\mathrm{H}^{\prime}=2,9\right)$ e baixa densidade e dominância de $V$. divergens. As demais parcelas foram identificadas como formações monodominantes de $V$. divergens, devido à sua dominância de mais de $50 \%$ dentro de cada parcela.
\end{abstract}

Palavras-chave: estrutura, cambarazal, planície de inundação, monodominância, pulso de inundação.

\begin{abstract}
Phytosociology of a monodominant flooded forest of Vochysia divergens Pohl (Vochysiaceae) in North Pantanal, Mato Grosso State, Brazil). Monodominant forest formations of Vochysia divergens Pohl found in the Pantanal are called "Cambarazais". The climatic changes registered in pluri-annual cycles have been cited as responsible for the sudden spread of these formations into seasonally flooded open areas. This study was carried out at the SESC Pantanal RPPN (Private Natural Heritage Reserve), Barão de Melgaço, Mato Grosso (Brazil), as part of the Long Term Ecological Research Program (PELD). It aims to analyze structural and phytosociological data collected in four areas of one hectare each of "cambarazal" along a hydro-topographical gradient. All individuals with cbh (circumference at breast height) $\geq 5 \mathrm{~cm}$ were identified, perimeters were measured and heights were estimated. In the entire sample area, 3,149 individuals belonging to 83 species were registered. Species diversity along the gradient showed an inverse relationship with floodwater levels. The plot with the lowest level of flooding (P1) had the highest species diversity index $\left(\mathrm{H}^{\prime}=2.91\right)$ of the sampled plots and the lowest values of $V$. divergens density and dominance. The other plots were considered to be $V$. divergens monodominant formations, since relative dominance of this species in these areas was greater than $50 \%$.
\end{abstract}

Key words: forest structure, cambarazal, floodplain, monodominance, flood pulse

\section{Introdução}

Áreas úmidas cobrem no mundo cerca de 250 milhões de hectares, tendo uma grande importância nos ciclos biogeoquímicos e como habitats para a vida silvestre de todos os tipos. Nestas áreas, a saturação ou completo alagamento do solo pela água superficial ou subterrânea seleciona organismos com adaptações para viver em solos mal drenados (Lugo 1990).

Diferente de outras áreas úmidas, o pantanal é uma planície intermitente e sazonalmente inundada. A flutuação anual do nível da água - o pulso de inundação
- regula os processos ecológicos que ali ocorrem (Junk et al. 1989). As diferenças locais do regime hidrológico, somadas às variações da topografia e do solo, proporcionam zonas permanente e periodicamente alagadas (Aquatic/Terrestrial Transition Zones - ATTZ) e outras raramente alagadas (Junk et al. 1989, Nunes da Cunha \& Junk 2001). Segundo Nunes da Cunha \& Junk (1999), apenas 5\% das espécies arbóreas no pantanal habitam, exclusivamente, zonas com prolongado alagamento, enquanto $30 \%$ estão restritas às áreas raramente alagadas e $65 \%$ são de ampla distribuição no gradiente.

\footnotetext{
1 Universidade Federal de Mato Grosso, Departamento de Botânica e Ecologia, NEPA-IB/UFMT, Av. Fernando Corrêa da Costa s/n, Bairro Coxipó, 78060-900 Cuiabá, MT, Brasil

2 Autor para correspondência: juarieira@yahoo.com.br
} 
As freqüentes oscilações dos níveis da inundação que ocorrem no pantanal, causadas pela variação pluviométrica e mudanças na dinâmica sedimentológica ao longo do tempo (Collischonn et al. 2001), podem funcionar como um filtro ao estabelecimento e desenvolvimento de algumas espécies de plantas (van der Valk 1981). Estas variações levam-nas a enfrentar mudanças freqüentes e fundamentais das condições ambientais dos habitats, como as de extremo estresse hídrico, seja pela falta ou pelo excesso de água (Junk \& Da Silva 1999). Esta condição tem levado à permanência de grande quantidade de espécies pioneiras no pantanal, que mantêm suas populações em altas densidades, de acordo com os requerimentos fisiológicos e ecológicos da espécie (Pott \& Pott 1994; Silva et al. 2000). Este é o caso de Tabebuia aurea (Silva Manso) Benth. \& Hook. f. ex S. Moore (Bignoniaceae), Copernicia alba Morong (Arecaceae) e Vochysia divergens Pohl (Vochysiaceae), espécies que formam estandes monodominantes no pantanal, localmente chamados de paratudal, carandazal e cambarazal, respectivamente (Nascimento \& Nunes da Cunha 1989; Pott \& Pott 1994; PCBAP 1997). Segundo Connell \& Lowman (1989), a dominância (ou outro parâmetro, como densidade e valor de cobertura) de mais de $50 \%$ de uma única espécie formadora do dossel determina a monodominância de estandes florestais. As causas da ocorrência de tais formações monodominantes ainda são bastante discutidas, porém já existem algumas evidências neste sentido, como a presença de distúrbio atuando em algumas destas comunidades, onde poucas espécies conseguem se estabelecer (Nascimento \& Nunes da Cunha 1989; Hart 1990; Ikeda-Castrillon et al. 2001; Parolin et al. 2002).

Diferentes respostas das plantas às condições do habitat mostram que algumas espécies podem servir de indicação de mudanças ambientais. Este é o caso de Vochysia divergens, uma espécie cuja distribuição está justamente relacionada às áreas periodicamente inundáveis do pantanal (Stafleu 1948; Prance \& Schaller 1982; Nunes da Cunha \& Junk 1999) e que, nos últimos anos, tem se espalhado rapidamente pelos campos naturais e manejados, formando extensos estandes de cambarazal (Nunes da Cunha \& Oliveira 2001; Nunes da Cunha \& Junk 2004). Estimou-se que, em 1994, cambarazais haviam ocupado entre 5 a 7\% da sub-região do pantanal de Poconé (Faßenacht 1995). No pantanal, proprietários de fazenda de gado foram os primeiros a alertar sobre a "invasão" do cambará, visto que seus campos estavam sendo essencialmente cobertos por $V$. divergens e, assim, tornando-se indisponíveis para pastagem (Nunes da Cunha et al. 2000).

A causa de seu espalhamento parece estar relacionada à presença de ciclos plurianuais de inundação, nos quais períodos de grandes cheias e secas que ocorrem no pantanal, em intervalos plurianuais, acarretam a retração e o aumento das populações do cambará, dando à vegetação um caráter irregular no tempo e no espaço (Junk \& Da Silva 1999; Nunes da Cunha \& Junk 2001; Junk 2002). Nunes da Cunha \& Junk (2004) atentam para a coincidência da entrada de um período plurianual de grande cheia no pantanal, iniciado em 1974, com o espalhamento de algumas espécies lenhosas, tais como: Licania parvifolia Huber, Combretum lanceolatum Pohl e Vochysia divergens.

Vochysia divergens apresenta características ecológicas e fisiológicas que favorecem seu rápido espalhamento e dominância em campos sazonalmente inundados. Sua alta taxa de crescimento sob intensa luminosidade, sua tolerância à condição de prolongado alagamento, a capacidade de suas plântulas para manter suas folhas intactas embaixo da superfície da água e a grande produção de sementes espalhadas pelo vento e água são algumas delas. A despeito disto, essa espécie tem baixa tolerância ao estresse da seca, tendo suas populações reduzidas pelo efeito de períodos plurianuais de grandes secas (Nunes da Cunha et al. 2000; Nunes da Cunha \& Junk 2004).

O presente estudo, inserido no âmbito do Programa de Pesquisa Ecológica de Longa Duração (PELD), testou a hipótese de que a estrutura da comunidade de cambarazal varia em função do gradiente de inundação. Neste cenário é provável que se encontre em parcelas mais secas, em função da diminuição da altura da lâmina de água, uma maior diversidade de espécies e conseqüente diminuição da dominância do cambará. O objetivo deste trabalho foi avaliar qual a relação existente entre formações de floresta monodominante de Vochysia divergens Pohl e a inundação, comparando os parâmetros fitossociológicos da comunidade em diferentes níveis de inundação.

\section{Material e métodos}

Área de estudo - No Estado de Mato Grosso, cambarazais são encontrados, em geral, nos municípios de Barão de Melgaço, Cáceres, Poconé e Santo Antônio de Leverger (Nascimento \& José 1986). Segundo Veloso (1972), a vegetação do pantanal de Barão de Melgaço é, majoritariamente, da formação dos cerrados (cerca de $58 \%$ ), com cerca de $9,3 \%$ da formação cambarazal.

O cambarazal estudado (Fig. 1) forma uma faixa 
contínua, com cerca de $25 \mathrm{~km}$ de extensão e $4 \mathrm{~km}$ de largura, paralela ao rio Cuiabá, a uma distância deste de aproximadamente $14 \mathrm{~km}$, entre o porto Biguazal e o posto Espírito Santo, na RPPN (Reserva Particular do Patromônio Natural / Sistema Nacional de Unidades de Conservação - SNUC) Estância Ecológica SESC (Serviço Social do Comércio) Pantanal, município de Barão de Melgaço, Estado de Mato Grosso, Brasil (entre $16^{\circ}$ e $18^{\circ} \mathrm{S}$ e $56^{\circ}$ e $58^{\circ} \mathrm{W}$ ).

O clima local está na classe Aw, que corresponde a invernos secos e verões chuvosos, com precipitação anual entre 1.000 e 1.500 mm (Köppen 1948). Dentro da RPPN, a temperatura oscila entre $22{ }^{\circ} \mathrm{C}$ e $32{ }^{\circ} \mathrm{C}$, estando as áreas mais frescas dentro da reserva (com cerca de $21{ }^{\circ} \mathrm{C}$ de temperatura) associadas às áreas de mata (Hasenack et al. 2003).

O valor altimétrico dentro da RPPN está acima de $80 \mathrm{~m}$ e não ultrapassa os $150 \mathrm{~m}$ de altitude, variação esta encontrada no pantanal mato-grossense (RadamBrasil 1982).

A inundação que ocorre na área de estudo é um reflexo da variação anual do nível de água que ocorre no rio Cuiabá e é altamente influenciada pela precipitação local e difícil drenagem da água da chuva pelo solo. A inundação acompanha o período de chuva que vai de outubro a setembro. O padrão de inundação é do tipo monomodal, com pequena amplitude (Hamilton et al. 1996). Além dos ciclos anuais de inundação também são reconhecidos ciclos plurianuais de inundação, com períodos de grandes cheias e grandes secas (Collischonn et al. 2001; Nunes da Cunha \& Junk 2001).

Coleta e análise de dados - Para a coleta de dados fitossociológicos e florísticos utilizaram-se quatro parcelas (P1, P2, P3 e P4) de 1 ha cada $(100 \times 100 \mathrm{~m})$, subdivididas em sub-parcelas de $10 \times 10 \mathrm{~m}$. As parcelas foram distribuídas ao longo do gradiente de inundação, contemplando diferentes estandes de cambarazal (Fig. 1). As parcelas centrais (P3 e P4) apresentam um dossel alto (cerca de $28 \mathrm{~m}$ ) e há pouca entrada de luz. Nestas parcelas o sub-bosque é ralo, exceto nas áreas de clareira onde este se adensa. Por se encontrarem no interior da floresta, estas parcelas parecem passar por menores ameaças de entrada de fogo do que as parcelas localizadas nas áreas de borda (P1 e P4). A parcela P4, a área mais próxima ao rio Cuiabá dentre as parcelas estudadas, é margeada por campo sujo inundável e apresenta uma maior entrada de luz no seu sub-bosque do que as parcelas centrais. Esta parcela é a primeira a receber a água proveniente do transbordamento do rio Cuiabá no período de cheia. A parcela P1 apresenta características bastante distintas das demais: possui

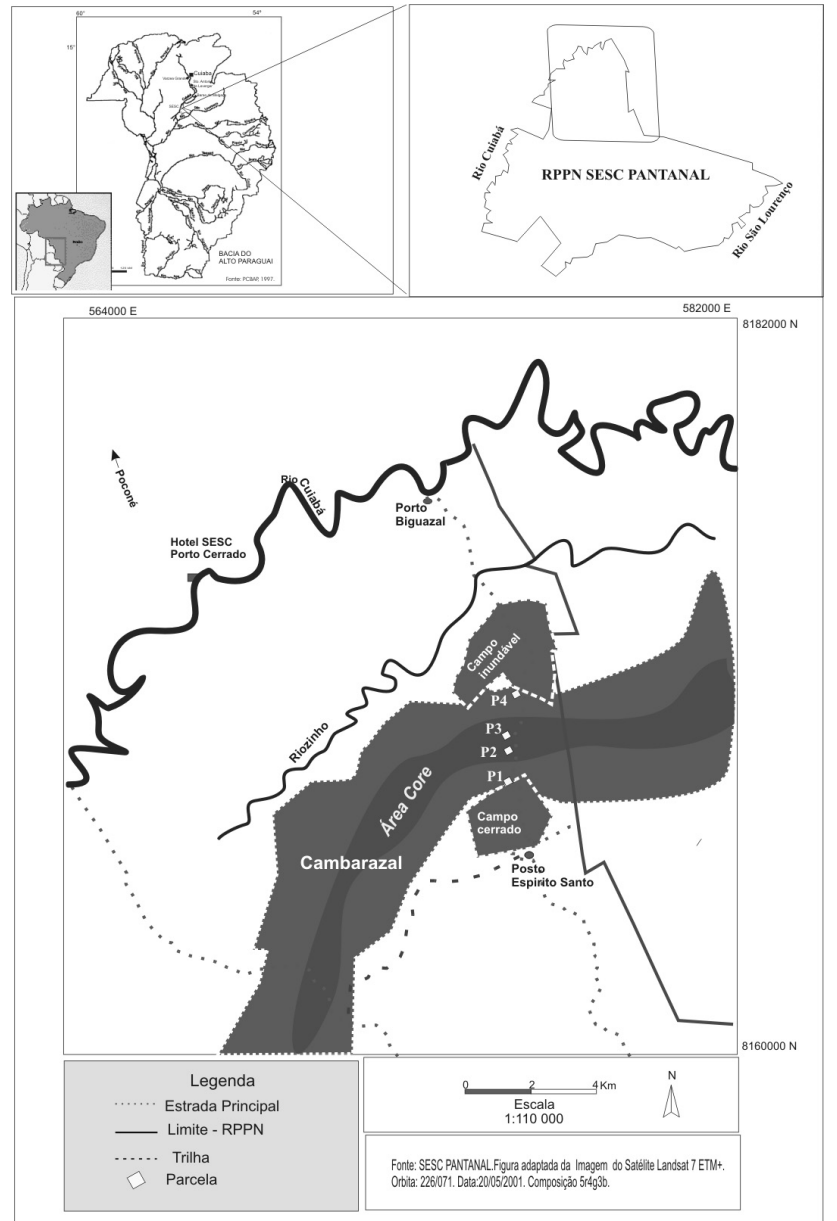

Figura 1. Localização do cambarazal e das parcelas amostrais (P1, P2, P3 e P4), na RPPN SESC Pantanal, Barão de Melgaço, Mato Grosso (Brasil).

fisionomia savânica e está localizada no limite mais seco do gradiente de inundação e também no limite entre o cambarazal e o cerrado.

De todos os indivíduos, vivos e mortos (em pé), com CAP (Circunferência à Altura do Peito) $\geq 5 \mathrm{~cm}$ foram tomadas suas medidas de circunferência e estimadas as alturas.

Para fins de monitoramento em longo prazo, todos os indivíduos amostrados foram marcados com placas de alumínio, devidamente numeradas. Em casos de plantas com múltiplos caules, cada um deles foi medido separadamente, e a soma de suas áreas basais foi considerada a área basal da planta.

Os parâmetros fitossociológicos calculados foram aqueles de uso mais comum em estudos desta natureza e estiveram de acordo com Mueller-Dombois \& Ellenberg (1974). O valor de importância (soma da densidade, freqüência e dominância relativas) de cada espécie foi calculado, segundo Kent \& Coker (1992).

Foram confeccionadas curvas de incremento de 
espécie para cada parcela amostrada, tendo em vista a verificação da suficiência amostral, na representação florística de cada estande de cambarazal.

A diversidade de espécies de cada parcela foi calculada com base nos índices de diversidade Shannon-Wienner (H'; Log Natural) e de Eqüabilidade de Pielou (J') (Magurran 1988). Esta indica a relação entre número de espécies e sua abundância dentro da comunidade (na própria parcela). O programa MVSP (Multivariante Statistical Package, versão 2, disponibilizado por Kovack, Warren) foi utilizado para realizar os cálculos dos índices acima. A similaridade existente entre as parcelas (índice de Sørensen) (Sørensen 1948) foi calculada através do programa MVSP (Kovach 1993). Esta relaciona as diferenças de composição de espécies (grau de complementaridade) entre as comunidades (entre as parcelas) (Magurran 1988). O índice de Sørensen varia de 0 (zero) a 1 (um) e, geralmente, quando maior que 0,5 é considerado alto (Fonseca \& Silva Junior 2004). Este critério foi também utilizado no presente estudo para definir as similaridades entre parcelas. Um dendograma de similaridade com base nos resultados da matriz de similaridade foi gerado segundo técnicas a agrupamento pela associação média não ponderada (UPGMA).

A altura da lâmina de água de cada parcela foi medida, mensalmente, durante o período de cheia, em um único ponto por parcela. Os dados do mês de janeiro não foram coletados em função da impossibilidade de acesso à área de estudo. Foram utilizados para a realização das medições: uma régua de alumínio, uma corda com peso na extremidade e uma trena.

Testes de regressão linear, relacionando os valores de diversidade de espécies e os de dominância absoluta do cambará, aos dados de inundação, também foram realizados (Gotelli \& Ellison 2004). Análise de variância e teste Tukey foram realizados com os dados de inundação, considerando valores de $P \leq 0.05$ para rejeição da hipótese nula.

\section{Resultados e discussão}

Nos quatro hectares amostrados, foram levantados 3.149 indivíduos, dos quais 2.800 vivos e 349 mortos em pé, representando respectivamente $89 \%$ e $11 \%$ daquele total. $\mathrm{O}$ conjunto florístico foi representado por 83 espécies, sendo 58 em P1, 19 em P2, 29 em P3 e 26 em P4 (Tab. 1).

A parcela P1 apresenta uma marcada diferenciação estrutural em relação às demais parcelas, destacando-se a diferença entre número de troncos e indivíduos (Tab.
1). Tal diferença tem sido considerada uma adaptação das espécies a condições ambientais extremas (Nunes da Cunha \& Junk 2001). É provável que o fogo e/ou

Tabela 1. Número de indivíduos ( $\mathrm{N}$ ind.; incluindo os mortos), número de troncos ( $\mathrm{N}$ tronc.), número de indivíduos mortos ( $\mathrm{N}$ mort.) e riqueza de espécies (S), em cada uma das parcelas amostrais (P1 a P4), na RPPN SESC Pantanal, Barão de Melgaço, Mato Grosso (Brasil). Médias \pm desvio padrão (DP).

\begin{tabular}{lcccc}
\hline Parcela & N. ind. & N. tronc. & N. mort. & S \\
\hline P1 & 1.050 & 3.336 & 10 & 58 \\
P2 & 742 & 1.033 & 187 & 19 \\
P3 & 441 & 692 & 101 & 29 \\
P4 & 916 & 1.741 & 51 & 26 \\
Média \pm DP & $787 \pm 263$ & $1.701 \pm 1.175$ & $86 \pm 76$ & $33 \pm$ \\
17 & & & & \\
Total & 3.149 & 6.802 & 349 & 83 \\
\hline
\end{tabular}

a inundação estejam promovendo a emissão de ramos secundários pelas plantas. Não há relatos nem indícios de manejo florestal nestas áreas, o que poderia levar ao perfilhamento dos indivíduos. Coutinho (1990) ressalta a importância do fogo no cerrado, onde muitas espécies emitem ramos secundários como mecanismo adaptativo. As parcelas P1 e P4 apresentaram o maior número de indivíduos entre as parcelas. As parcelas $\mathrm{P} 3$ e $\mathrm{P} 4$, a despeito de terem números de espécies semelhantes, não têm a mesma relação de número de indivíduos, sendo encontrado em $\mathrm{P} 4$ o dobro do número de indivíduos de P3. Esta diferença deve-se ao maior número de indivíduos por espécie na $\mathrm{P} 4$; diferente do que ocorreu na parcela P3, em que as espécies presentes foram representadas por poucos indivíduos. A parcela $\mathrm{P} 3$ representa um estádio sucessional mais avançado desta comunidade, onde, provavelmente, o processo de colonização do cambará iniciou-se. A quantidade de indivíduos mortos da parcela P4 parece não expressar a real mortalidade ocorrida nesta área. Isto pode ser evidenciado pela maior freqüência de indivíduos jovens, de hábito arbóreo, encontrados nesta parcela, indicando um processo regenerativo. Este alto índice de plantas jovens deve prever aquelas não contabilizadas, pela ação de queimadas, fruto de sua maior susceptibilidade ao fogo e a outros distúrbios. A parcela P2 apresentou a menor riqueza de espécies entre as parcelas, da mesma maneira que exibiu a maior quantidade de indivíduos mortos. A alta incidência de mortos nesta área parece estar relacionada à passagem de fogo (grande queimada no ano de 1999 na RPPN, J. Bueno, com. pes.) testemunhada pelas marcas de 
queima no tronco das árvores.

Os valores de altura da lâmina de água diferiram significantemente entre as parcelas $(P=0,002)$. A P3 apresentou o maior valor de altura da lâmina de água máxima $(1,37 \mathrm{~m})$, seguida pela $\mathrm{P} 4(1,26 \mathrm{~m}), \mathrm{P} 2$ $(0,90 \mathrm{~m})$ e P1 (0,64 m) (Fig. 2). Todos estes valores foram alcançados no mês de março. Estes dados mostram o efeito preponderante da microtopografia sobre a dinâmica hidrológica local, onde a definição das áreas de maior permanência e de maior altura da lâmina de água é dirigida pelo gradiente entre a depressão e o plano (Carvalho 1986).

A forma da curva de incremento de espécies variou entre as parcelas (Fig. 3). Na P1, a curva não se estabilizou, corroborando o caráter transicional deste estande. Nas demais parcelas, as curvas mostraram uma tendência a alcançar a estabilidade. Nestas áreas, a alta inundação parece ser o fator determinante do estabelecimento das espécies, diminuindo a riqueza de espécies. O tamanho da área não deve ter um grande efeito sobre a riqueza de espécies dentro de áreas úmidas florestadas (Keogh 1999).

É possível observar, através da tabela de dados fitossociológicos das espécies, que na parcela P1 (Tab. 2), Vochysia divergens apresenta baixo valor de importância (VI $=3,33 \%)$, devido aos seus baixos valores de densidade $(\mathrm{DA}=23)$ e dominância $(\mathrm{DoA}=0,32$ $\left.\mathrm{m}^{2} \mathrm{ha}^{-1}\right)$. Isto indica a presença de poucos e jovens indivíduos de cambará nesta parcela. Nas outras três parcelas, $V$. divergens obteve o mais alto valor de importância entre as espécies, com 40,5\%, 53,8\% e

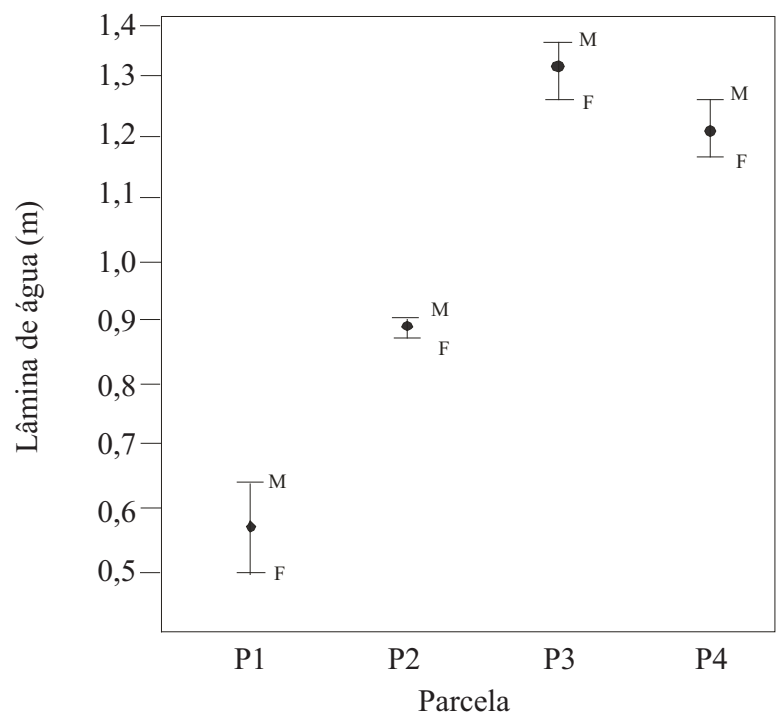

Figura 2. Variação da altura da lâmina de água (m) nos meses de fevereiro (F) e março (M) de 2004, nas quatro parcelas estudadas (P1, P2, P3 e P4).

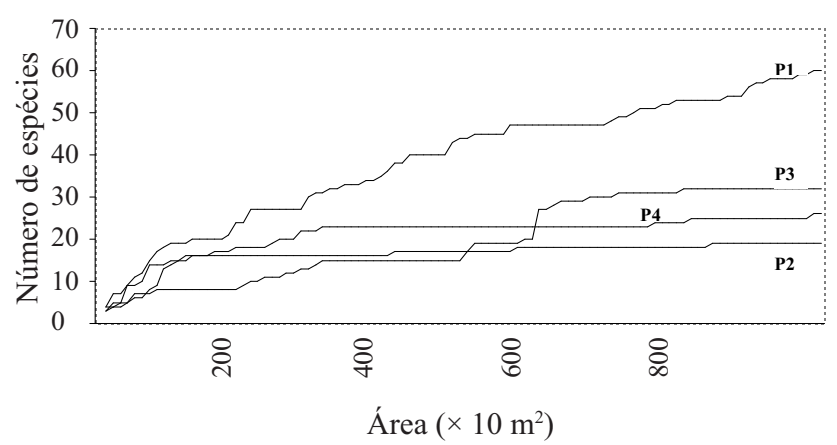

Figura 3. Curva de incremento de espécies com CAP $\geq 5 \mathrm{~cm}$, amostradas nas quatro parcelas de 1 ha $(100 \times 100 \mathrm{~m})(\mathrm{P} 1 \mathrm{a}$ P4), no SESC Pantanal. Barão de Melgaço, Mato Grosso (Brasil).

$51,3 \%$, seguindo a ordem crescente das parcelas (Tab. 3, 4 e 5). A densidade e, principalmente, a dominância do cambará foram responsáveis pelos altos valores de importância encontrados. Se considerados na análise fitossociológica, os indivíduos mortos se destacariam por apresentarem o segundo maior VI nas parcelas P2 (VI=21,11\%) e P3 (VI = 17,74\%). Duroia duckei Huber foi um elemento que se destacou na fisionomia do cambarazal, apresentando o segundo maior VI nas parcelas centrais (Tab. 3 e 4). Na P4 (Tab. 5), Ocotea longifolia Kunth (Lauraceae) apresenta o segundo maior VI da parcela (VI $=8,47 \%$ ).

Em função de suas características estruturais, a parcela P1 pode ser classificada como um estande de cerrado. A fim de situar estes resultados entre os obtidos por outros estudos fitossociológicos, fizeram-se as comparações abaixo. Para isto, foram considerados os diferentes critérios de inclusão de indivíduos, utilizados por cada autor. Assim, na parcela P1, a densidade absoluta total (786 ind ha-1) foi inferior à encontrada em duas outras áreas de cerrado: uma em Cuiabá, MT (1686 ind ha ${ }^{-1}$ ) (Nascimento \& Saddi 1992), a outra no sul do Estado de Mato Grosso, na baixada cuiabana (1888 ind ha-1) (Oliveira Filho et al. 1989). Os resultados de densidade, descritos por Nunes da Cunha \& Junk (1999) em uma mata de cordilheira no pantanal (862 ind ha-1) e por Nascimento \& Nunes da Cunha (1989), num cambarazal no pantanal (631 ind ha ${ }^{-1}$ ), foram similares aos encontrados na parcela P4 (781 ind ha $^{-1}$ ) e P2 (635 ind ha ${ }^{-1}$ ). Marimon \& Felfili (2000) e Isaacs et al. (1996) apresentaram valores de densidade absoluta, numa floresta monodominante de Brosimum rubescens Taub., na reserva indígena Areões, Água Boa, MT (488 ind ha ${ }^{-1}$ ) e numa floresta monodominante de Dicymbe altsonii Sandwith, na Guiana (488 ind $\left.\mathrm{ha}^{-1}\right)$, respectivamente, próximos ao encontrado na P3 (376 ind ha-1). 
Tabela 2. Relação das espécies, em ordem decrescente de VI (\%), presentes na parcela P1 e seus respectivos parâmetros fitossociológicos (DA = densidade absoluta; $\mathrm{DR}=$ densidade relativa; $\mathrm{FA}=$ freqüência absoluta; $\mathrm{FR}=$ freqüência relativa; DoA $=$ dominância absoluta; $\mathrm{DoR}=$ dominância relativa; $\mathrm{VI}$ = valor de importância, total e em percentagem). Barão de Melgaço, Mato Grosso (Brasil).

\begin{tabular}{|c|c|c|c|c|c|c|c|c|}
\hline Espécie & DA & $\begin{array}{l}\text { DR } \\
(\%)\end{array}$ & FA & $\begin{array}{l}\text { FR } \\
(\%)\end{array}$ & $\begin{array}{c}\text { DoA } \\
\left(\mathrm{m}^{2} \mathrm{ha}^{-1}\right)\end{array}$ & $\begin{array}{l}\text { DoR } \\
(\%)\end{array}$ & VI & $\begin{array}{l}\text { VI } \\
(\%)\end{array}$ \\
\hline Byrsonima orbignyana A. Juss. & 162 & 15,58 & 59 & 11,61 & 0,89 & 13,03 & 40,23 & 13,41 \\
\hline Alchornea discolor Poepp. & 187 & 17,98 & 57 & 11,22 & 0,20 & 2,86 & 32,06 & 10,69 \\
\hline Bactris glaucescens Drude & 56 & 5,38 & 42 & 8,27 & 1,14 & 16,56 & 30,21 & 10,07 \\
\hline Licania parvifolia Huber & 65 & 6,25 & 36 & 7,09 & 0,65 & 9,53 & 22,87 & 7,62 \\
\hline Curatella americana L. & 23 & 2,21 & 19 & 3,74 & 0,99 & 14,45 & 20,41 & 6,80 \\
\hline Erythroxylum anguifugum Mart. & 101 & 9,71 & 42 & 8,27 & 0,06 & 0,82 & 18,80 & 6,27 \\
\hline Mabea sp. & 89 & 8,56 & 29 & 5,71 & 0,27 & 3,91 & 18,18 & 6,06 \\
\hline Bauhinia cuiabensis Steud. & 57 & 5,48 & 34 & 6,69 & 0,03 & 0,37 & 12,55 & 4,18 \\
\hline Callisthene fasciculata Mart. & 22 & 2,12 & 11 & 2,17 & 0,48 & 6,96 & 11,24 & 3,75 \\
\hline Vochysia divergens Pohl & 23 & 2,21 & 15 & 2,95 & 0,32 & 4,73 & 9,89 & 3,30 \\
\hline Dipteryx alata Vogel & 9 & 0,87 & 8 & 1,57 & 0,35 & 5,16 & 7,60 & 2,53 \\
\hline Duroia duckei Huber & 27 & 2,60 & 21 & 4,13 & 0,02 & 0,26 & 6,99 & 2,33 \\
\hline Cupania vernalis Cambess. & 52 & 5,00 & 5 & 0,98 & 0,03 & 0,48 & 6,46 & 2,15 \\
\hline Tabebuia aurea (Silva Manso) Benth. \& Hook. f. ex S. Moore & 9 & 0,87 & 8 & 1,57 & 0,26 & 3,83 & 6,27 & 2,09 \\
\hline Helicteres guazumaefolia Kunth & 22 & 2,12 & 18 & 3,54 & 0,04 & 0,57 & 6,23 & 2,08 \\
\hline Qualea parviflora Mart. & 3 & 0,29 & 3 & 0,59 & 0,30 & 4,43 & 5,31 & 1,77 \\
\hline Sclerolobium paniculatum Vogel & 8 & 0,77 & 7 & 1,38 & 0,21 & 3,01 & 5,16 & 1,72 \\
\hline Couepia uiti (Mart. \& Zucc.) Benth. ex Hook. f. & 10 & 0,96 & 9 & 1,77 & 0,04 & 0,65 & 3,38 & 1,13 \\
\hline Dalbergia riedelii (Benth.) Sandwith & 4 & 0,38 & 4 & 0,79 & 0,14 & 1,99 & 3,17 & 1,06 \\
\hline Genipa americana L. & 7 & 0,67 & 7 & 1,38 & 0,07 & 1,05 & 3,10 & 1,03 \\
\hline Tabebuia heptaphylla (Vell.) Toledo & 12 & 1,15 & 5 & 0,98 & 0,05 & 0,76 & 2,90 & 0,97 \\
\hline Copaifera langsdorffi Desf. & 6 & 0,58 & 5 & 0,98 & 0,08 & 1,13 & 2,69 & 0,90 \\
\hline Eugenia sp. 1 & 7 & 0,67 & 5 & 0,98 & 0,007 & 0,09 & 1,75 & 0,58 \\
\hline Brosimum gaudichaudii Trécul & 9 & 0,87 & 4 & 0,79 & 0,005 & 0,07 & 1,73 & 0,58 \\
\hline Diospyros odorata Hiern ex Greves & 6 & 0,58 & 5 & 0,98 & 0,008 & 0,11 & 1,67 & 0,56 \\
\hline Myrtaceae 6 & 7 & 0,67 & 3 & 0,59 & 0,009 & 0,13 & 1,39 & 0,46 \\
\hline Erythroxylum deciduum A. St.-Hil. & 4 & 0,38 & 4 & 0,79 & 0,003 & 0,05 & 1,22 & 0,41 \\
\hline Banara arguta Briq. & 6 & 0,58 & 3 & 0,59 & 0,002 & 0,03 & 1,20 & 0,40 \\
\hline Buchenavia oxycurpa (Mart.) Eichler & 1 & 0,10 & 1 & 0,20 & 0,05 & 0,77 & 1,06 & 0,35 \\
\hline Tocoyena formosa (Cham. \& Schltdl.) K. Schum. & 3 & 0,29 & 3 & 0,59 & 0,003 & 0,05 & 0,93 & 0,31 \\
\hline Acosmium sp. & 1 & 0,10 & 2 & 0,39 & 0,03 & 0,38 & 0,87 & 0,29 \\
\hline Guibourtia hymenifolia (Moric.) J. Léonard & 1 & 0,10 & 1 & 0,20 & 0,03 & 0,45 & 0,74 & 0,25 \\
\hline Vitex cymosa Bertero ex Spreng. & 2 & 0,19 & 2 & 0,39 & 0,008 & 0,12 & 0,71 & 0,24 \\
\hline Salacia elliptica (Mart. ex Schult.) G. Don & 3 & 0,29 & 2 & 0,39 & 0,002 & 0,03 & 0,71 & 0,24 \\
\hline Vochysia tucanorum Mart. & 2 & 0,19 & 2 & 0,39 & 0,01 & 0,08 & 0,67 & 0,22 \\
\hline Myrtaceae 5 & 1 & 0,10 & 1 & 0,20 & 0,02 & 0,34 & 0,63 & 0,21 \\
\hline Ocotea longifolia Kunth & 2 & 0,19 & 2 & 0,39 & 0,003 & 0,04 & 0,63 & 0,21 \\
\hline Peritassa dulcis (Benth.) Miers & 2 & 0,19 & 2 & 0,39 & 0,002 & 0,03 & 0,62 & 0,21 \\
\hline Annona cornifolia A. St.-Hil. & 4 & 0,38 & 1 & 0,20 & 0,001 & 0,02 & 0,60 & 0,20 \\
\hline Combretum lanceolatum Pohl ex Eichler & 2 & 0,19 & 2 & 0,39 & 0,001 & 0,01 & 0,60 & 0,20 \\
\hline Leguminosae sp. & 2 & 0,19 & 2 & 0,39 & 0,001 & 0,01 & 0,59 & 0,20 \\
\hline Licania minutiflora (Sagot) Fritsch & 2 & 0,19 & 1 & 0,20 & 0,01 & 0,19 & 0,58 & 0,19 \\
\hline Tabebuia serratifolia (Vahl) G. Nicholson & 2 & 0,19 & 1 & 0,20 & 0,006 & 0,08 & 0,47 & 0,16 \\
\hline Psychotria carthagenensis Jacq. & 2 & 0,19 & 1 & 0,20 & 0,005 & 0,07 & 0,46 & 0,15 \\
\hline Erythroxylum daphnites Mart. & 2 & 0,19 & 1 & 0,20 & 0,001 & 0,01 & 0,40 & 0,13 \\
\hline Rhamnidium elaeocarpum Reiss. & 1 & 0,10 & 1 & 0,20 & 0,005 & 0,07 & 0,36 & 0,12 \\
\hline Andira inermis (W. Wright) Kunth ex DC. & 1 & 0,10 & 1 & 0,20 & 0,003 & 0,05 & 0,34 & 0,11 \\
\hline Luehea paniculata Mart. & 1 & 0,10 & 1 & 0,20 & 0,002 & 0,03 & 0,32 & 0,11 \\
\hline Marchaerium acutifolium Vogel & 1 & 0,10 & 1 & 0,20 & 0,001 & 0,02 & 0,31 & 0,10 \\
\hline Bunchosia sp. & 1 & 0,10 & 1 & 0,20 & 0,001 & 0,02 & 0,31 & 0,10 \\
\hline Mimosa pellita Humb. \& Bonpl. ex Willd. & 1 & 0,10 & 1 & 0,20 & 0,001 & 0,02 & 0,31 & 0,10 \\
\hline Albizia sp. & 1 & 0,10 & 1 & 0,20 & 0,001 & 0,01 & 0,30 & 0,10 \\
\hline Cenostigma macrophyllum Tul. & 1 & 0,10 & 1 & 0,20 & 0,001 & 0,01 & 0,30 & 0,10 \\
\hline Mouriri guianensis Aubl. & 1 & 0,10 & 1 & 0,20 & 0,001 & 0,01 & 0,30 & 0,10 \\
\hline
\end{tabular}

Tabela 2 (continuação) 


\begin{tabular}{|c|c|c|c|c|c|c|c|c|}
\hline Espécie & DA & $\begin{array}{l}\text { DR } \\
(\%)\end{array}$ & FA & $\begin{array}{l}\text { FR } \\
(\%)\end{array}$ & $\begin{array}{c}\text { DoA } \\
\left(\mathrm{m}^{2} \mathrm{ha}^{-1}\right)\end{array}$ & $\begin{array}{l}\text { DoR } \\
(\%)\end{array}$ & VI & $\begin{array}{l}\text { VI } \\
(\%)\end{array}$ \\
\hline Pterocarpus rohrii Vahl & 1 & 0,10 & 1 & 0,20 & 0,001 & 0,01 & 0,30 & 0,10 \\
\hline Eugenia biflora (L.) DC. & 1 & 0,10 & 1 & 0,20 & 0,001 & 0,01 & 0,30 & 0,10 \\
\hline Inga vera Willd. & 1 & 0,10 & 1 & 0,20 & 0,0005 & 0,01 & 0,30 & 0,10 \\
\hline Bauhinia cf. mollis (Bong.) Dietr. & 1 & 0,10 & 1 & 0,20 & 0,0002 & 0,003 & 0,30 & 0,10 \\
\hline Total & 1.040 & 100 & 508 & 100 & 6,86 & 100 & 300 & 100 \\
\hline
\end{tabular}

Tabela 3. Relação das espécies, em ordem decrescente de VI (\%), presentes na parcela P2 e seus respectivos parâmetros fitossociológicos $(\mathrm{DA}=$ densidade absoluta; $\mathrm{DR}=$ densidade relativa; $\mathrm{FA}=$ freqüência absoluta; $\mathrm{FR}=$ freqüência relativa; DoA $=$ dominância absoluta; DoR = dominância relativa; VI = valor de importância, total e em percentagem). Barão de Melgaço, Mato Grosso (Brasil).

\begin{tabular}{|c|c|c|c|c|c|c|c|c|}
\hline Espécie & DA & $\begin{array}{l}\text { DR } \\
(\%)\end{array}$ & FA & $\begin{array}{l}\text { FR } \\
(\%)\end{array}$ & $\begin{array}{c}\text { DoA } \\
\left(\mathrm{m}^{2} \mathrm{ha}^{-1}\right)\end{array}$ & $\begin{array}{l}\text { Dc } \\
(\%\end{array}$ & VI & $\begin{array}{l}\text { VI } \\
(\%)\end{array}$ \\
\hline Vochysia divergens Pohl & 118 & 21,26 & 70 & 23,10 & 19,89 & 77,05 & 121,42 & 40,47 \\
\hline Duroia duckei Huber & 86 & 15,50 & 45 & 14,85 & 3,02 & 11,71 & 42,06 & 14,02 \\
\hline Cecropia pachystachya Trécul & 129 & 23,24 & 48 & 15,84 & 0,44 & 1,71 & 40,80 & 13,60 \\
\hline Alchornea discolor Poepp. & 41 & 7,39 & 30 & 9,90 & 0,03 & 0,11 & 17,40 & 5,80 \\
\hline Ocotea longifolia Kunth & 59 & 10,63 & 19 & 6,27 & 0,12 & 0,45 & 17,35 & 5,78 \\
\hline Licania parvifolia Huber & 19 & 3,42 & 17 & 5,61 & 1,67 & 6,48 & 15,52 & 5,17 \\
\hline Inga vera Willd. & 22 & 3,96 & 15 & 4,95 & 0,10 & 0,37 & 9,28 & 3,09 \\
\hline Mabea sp. & 12 & 2,16 & 11 & 3,63 & 0,15 & 0,58 & 6,38 & 2,13 \\
\hline Copaifera langsdorffi Desf. & 14 & 2,52 & 6 & 1,98 & 0,03 & 0,13 & 4,63 & 1,54 \\
\hline Mouriri guianensis Aubl. & 9 & 1,62 & 7 & 2,31 & 0,12 & 0,47 & 4,40 & 1,47 \\
\hline Bunchosia sp. & 11 & 1,98 & 7 & 2,31 & 0,006 & 0,02 & 4,32 & 1,44 \\
\hline Pterocarpus cf. rohrii Vahl & 7 & 1,26 & 6 & 1,98 & 0,17 & 0,67 & 3,91 & 1,30 \\
\hline Triplaris americana $\mathrm{L}$. & 7 & 1,26 & 5 & 1,65 & 0,02 & 0,06 & 2,98 & 0,99 \\
\hline Leguminosae sp. & 7 & 1,26 & 4 & 1,32 & 0,01 & 0,04 & 2,62 & 0,87 \\
\hline Peritassa dulcis (Benth.) Miers & 5 & 0,90 & 5 & 1,65 & 0,003 & 0,01 & 2,56 & 0,85 \\
\hline Sapium obovatum Klotzsch ex Müll. Arg. & 4 & 0,72 & 3 & 0,99 & 0,002 & 0,01 & 1,72 & 0,57 \\
\hline Banara arguta Briq. & 3 & 0,54 & 3 & 0,99 & 0,001 & 0,004 & 1,53 & 0,51 \\
\hline Dalbergia riedelii (Benth.) Sandwith & 1 & 0,18 & 1 & 0,33 & 0,03 & 0,12 & 0,63 & 0,21 \\
\hline Myrtaceae 1 & 1 & 0,18 & 1 & 0,33 & 0,001 & 0,002 & 0,51 & 0,17 \\
\hline Total & 555 & 100 & 303 & 100 & 25,82 & 100 & 300 & 100 \\
\hline
\end{tabular}

Nota-se que a dominância relativa de $V$. divergens nas parcelas P2 (77,1\%), P3 $(86,2 \%)$ e P4 $(87,3 \%)$ foi superior a $50 \%$; o que, segundo Connell \& Lowman (1989), é critério para considerarmos tais florestas como monodominantes. Na mesma perspectiva de análise, estes valores são semelhantes ao de outra floresta monodominante de $V$. divergens, no pantanal de Poconé $(85,7 \%)$ (Nascimento \& Nunes da Cunha 1989), mas superiores aos de uma floresta rica em Peltogyne gracilipes Ducke, na Ilha Maracá, Roraima (49,38\%) (Nascimento \& Proctor 1997) e monodominante de Brosimum rubescens, na reserva indígena Areões, Água Boa, MT (58,85\%) (Marimon \& Felfili 2000).

Quando comparada a outros tipos de vegetação savânica, a parcela P1 apresentou valor de dominância absoluta ( $\left.\mathrm{DoA}=6,4 \mathrm{~m}^{2} \mathrm{ha}^{-1}\right)$ superior aos encontrados por Guarim Neto et al. (1994) (DoA =3,8 $\left.\mathrm{m}^{2} \mathrm{ha}^{-1}\right) \mathrm{e}$ inferior ao encontrado por Oliveira Filho et al. (1989) $\left(\right.$ DoA $\left.=21,91 \mathrm{~m}^{2} \mathrm{ha}^{-1}\right)$.

A comunidade presente nos estandes de cambarazal (P2, P3, P4) exibiu estratos bem definidos, ao contrário do observado na parcela de cerrado $(\mathrm{P} 1)$. $\mathrm{O}$ sub-bosque (estrato inferior) foi formado pelos indivíduos com alturas entre 1,3 e $10 \mathrm{~m}$; o estrato intermediário pelos indivíduos entre 10 e $20 \mathrm{~m}$; e o estrato superior (dominantes) por todos os indivíduos acima de $20 \mathrm{~m}$ de altura. Na parcela P1, cerca de $97 \%$ dos indivíduos amostrados apresentaram altura entre 1,3 e $10 \mathrm{~m}$. O segundo estrato foi composto por espécies como Genipa americana L., V. divergens e Tabebuia 
Tabela 4. Relação das espécies, em ordem decrescente de VI (\%), presentes na parcela P3 e seus respectivos parâmetros fitossociológicos (DA = densidade absoluta; $\mathrm{DR}=$ densidade relativa; $\mathrm{FA}=$ freqüência absoluta; $\mathrm{FR}=$ freqüência relativa; DoA $=$ dominância absoluta; $\mathrm{DoR}=$ dominância relativa; $\mathrm{VI}$ = valor de importância, total e em percentagem). Barão de Melgaço, Mato Grosso (Brasil).

\begin{tabular}{|c|c|c|c|c|c|c|c|c|}
\hline Espécie & DA & $\begin{array}{l}\text { DR } \\
(\%)\end{array}$ & FA & $\begin{array}{l}\text { FR } \\
(\%)\end{array}$ & $\begin{array}{c}\text { DoA } \\
\left(\mathrm{m}^{2} \mathrm{ha}^{-1}\right)\end{array}$ & $\begin{array}{l}\text { Do } \\
\text { (\% }\end{array}$ & VI & $\begin{array}{l}\text { VI } \\
(\%)\end{array}$ \\
\hline Vochysia divergens Pohl & 136 & 40,00 & 79 & 35,27 & 32,46 & 86,18 & 161,45 & $\overline{53,82}$ \\
\hline Duroia duckei Huber & 95 & 27,94 & 54 & 24,11 & 3,81 & 10,10 & 62,15 & 20,72 \\
\hline Mouriri guianensis Aubl. & 18 & 5,29 & 13 & 5,80 & 0,54 & 1,44 & 12,54 & 4,18 \\
\hline Coccoloba ochreolata Wedd. & 13 & 3,82 & 11 & 4,91 & 0,07 & 0,19 & 8,92 & 2,97 \\
\hline Inga vera Willd. & 10 & 2,94 & 9 & 4,02 & 0,03 & 0,08 & 7,04 & 2,35 \\
\hline Eugenia sp.1 & 8 & 2,35 & 6 & 2,68 & 0,003 & 0,01 & 5,04 & 1,68 \\
\hline Mabea sp. & 6 & 1,76 & 5 & 2,23 & 0,05 & 0,14 & 4,13 & 1,38 \\
\hline Sapium obovatum Klotzsch ex Müll. Arg. & 6 & 1,76 & 4 & 1,79 & 0,005 & 0,01 & 3,56 & 1,19 \\
\hline Peritassa dulcis (Benth.) Miers & 6 & 1,76 & 4 & 1,79 & 0,001 & 0,00 & 3,55 & 1,18 \\
\hline Alchornea discolor Poepp. & 4 & 1,18 & 4 & 1,79 & 0,04 & 0,11 & 3,07 & 1,02 \\
\hline Ocotea suaveolens Hassl. & 4 & 1,18 & 3 & 1,34 & 0,003 & 0,01 & 2,52 & 0,84 \\
\hline Pterocarpus cf. rohrii Vahl & 3 & 0,88 & 3 & 1,34 & 0,07 & 0,18 & 2,40 & 0,80 \\
\hline Cecropia pachystachya Trécul & 3 & 0,88 & 3 & 1,34 & 0,01 & 0,02 & 2,24 & 0,75 \\
\hline Ocotea longifolia Kunth & 4 & 1,18 & 2 & 0,89 & 0,04 & 0,11 & 2,18 & 0,73 \\
\hline Brosimopsis latescens S.Moore & 2 & 0,59 & 2 & 0,89 & 0,17 & 0,46 & 1,94 & 0,65 \\
\hline Albizia sp. & 2 & 0,59 & 2 & 0,89 & 0,16 & 0,41 & 1,89 & 0,63 \\
\hline Licania parvifolia Huber & 2 & 0,59 & 2 & 0,89 & 0,09 & 0,23 & 1,71 & 0,57 \\
\hline Celtis spinosa Cambess. & 2 & 0,59 & 2 & 0,89 & 0,03 & 0,08 & 1,56 & 0,52 \\
\hline Strichnos pseudoquina A. St.-Hil. & 2 & 0,59 & 2 & 0,89 & 0,007 & 0,02 & 1,50 & 0,50 \\
\hline Psidium sp. & 2 & 0,59 & 2 & 0,89 & 0,004 & 0,01 & 1,49 & 0,50 \\
\hline Bunchosia sp. & 2 & 0,59 & 2 & 0,89 & 0,003 & 0,01 & 1,49 & 0,50 \\
\hline Triplaris americana $\mathrm{L}$. & 2 & 0,59 & 2 & 0,89 & 0,003 & 0,01 & 1,49 & 0,50 \\
\hline Neea cf. hermaphrodita S. Moore & 1 & 0,29 & 1 & 0,45 & 0,05 & 0,13 & 0,87 & 0,29 \\
\hline Calophyllum brasiliensis Cambess. & 1 & 0,29 & 1 & 0,45 & 0,01 & 0,04 & 0,78 & 0,26 \\
\hline Acosmium sp. & 1 & 0,29 & 1 & 0,45 & 0,002 & 0,01 & 0,75 & 0,25 \\
\hline Myrtaceae 4 & 1 & 0,29 & 1 & 0,45 & 0,002 & 0,005 & 0,75 & 0,25 \\
\hline Cissus spinosa Cambess. & 1 & 0,29 & 1 & 0,45 & 0,001 & 0,003 & 0,74 & 0,25 \\
\hline Banafousia siphilitica (L.f.) L. Allorge & 1 & 0,29 & 1 & 0,45 & 0,001 & 0,002 & 0,74 & 0,25 \\
\hline Eugenia sp. & 1 & 0,29 & 1 & 0,45 & 0,0006 & 0,002 & 0,74 & 0,25 \\
\hline Casearia sp. & 1 & 0,29 & 1 & $0,45 \quad$ & 0,0004 & 0,001 & 0,74 & 0,25 \\
\hline Total & 340 & 100 & 224 & 100 & 37,67 & 100 & 300 & 100 \\
\hline
\end{tabular}

serratifolia (Vahl) G. Nicholson. O estrato superior não foi representado nesta parcela. Nas demais (P2, P3 e P4), o estrato inferior foi composto por Cecropia pachystachya, Mabea sp, Alchornea discolor Poepp. e Peritassa dulcis (Benth.) Miers, entre outras; o estrato intermediário por Duroia duckei, V. divergens e Ocotea longifolia; e o estrato superior foi dominado por $V$. divergens. Richards (1957) faz menção à presença de estratos bem definidos em florestas monodominantes em relação às florestas mistas, e ressalta a maior importância na definição da zona eufótica e da zona sombreada (sub-bosque), do que da própria estratificação das árvores. Estudos com comunidades vegetais em áreas úmidas ratificam as considerações feitas por esse autor, alertando sobre a consideração da altura de plantas como parâmetro para definição de estandes florestais, pois uma mesma espécie pode variar amplamente em altura entre diferentes habitats, em função da influência de diferentes condições ambientais (Lugo 1990).

A similaridade entre os estandes, verificada através do índice de Sørensen, confirma a distinção florística da parcela $\mathrm{P} 1$ em relação às demais (Fig. 4). As parcelas mais similares foram P2 e P3. No pantanal, a grande heterogeneidade espacial proporcionada por variações na topografia, nos solos e nos padrões de inundação (Nunes da Cunha \& Junk 2001) resulta numa paisagem onde as áreas mais próximas nem sempre se revelam as mais similares em relação às condições ambientais. É provável que a maior similaridade entre P2 e P3 seja resultado da proximidade entre si no processo sucessional.

A menor diversidade de espécies foi encontrada 
Tabela 5. Relação das espécies, em ordem decrescente de VI (\%), presentes na parcela P4 e seus respectivos parâmetros fitossociológicos $(\mathrm{DA}=$ densidade absoluta; $\mathrm{DR}=$ densidade relativa; FA $=$ freqüência absoluta; $\mathrm{FR}=$ freqüência relativa; DoA $=$ dominância absoluta; $\mathrm{DoR}=$ dominância relativa; $\mathrm{VI}=$ valor de importância, total e em percentagem). Barão de Melgaço, Mato Grosso (Brasil).

\begin{tabular}{|c|c|c|c|c|c|c|c|c|}
\hline Espécie & DA & $\begin{array}{l}\text { DR } \\
(\%)\end{array}$ & FA & $\begin{array}{l}\text { FR } \\
(\%)\end{array}$ & $\begin{array}{c}\text { DoA } \\
\left(\mathrm{m}^{2} \mathrm{ha}^{-1}\right)\end{array}$ & $\begin{array}{l}\text { Do } \\
(\%\end{array}$ & VI & $\begin{array}{l}\text { VI } \\
(\%)\end{array}$ \\
\hline Vochysia divergens Pohl & 379 & 43,82 & 87 & 22,89 & 25,82 & 87,31 & 154,02 & 51,34 \\
\hline Ocotea longifolia Kunth & 86 & 9,94 & 36 & 9,47 & 1,77 & 5,98 & 25,40 & 8,47 \\
\hline Peritassa dulcis (Benth.) Miers & 99 & 11,45 & 41 & 10,79 & 0,23 & 0,79 & 23,02 & 7,67 \\
\hline Bunchosia sp. & 51 & 5,90 & 32 & 8,42 & 0,08 & 0,28 & 14,59 & 4,86 \\
\hline Trichilia catigua A. Juss. & 41 & 4,74 & 33 & 8,68 & 0,23 & 0,76 & 14,19 & 4,73 \\
\hline Albizia polyantha (Spreng. F.) Lewis & 25 & 2,89 & 19 & 5,00 & 0,11 & 0,37 & 8,26 & 2,75 \\
\hline Eugenia sp. & 35 & 4,05 & 15 & 3,95 & 0,06 & 0,22 & 8,21 & 2,74 \\
\hline Psidium australe Cambess. & 27 & 3,12 & 17 & 4,47 & 0,08 & 0,25 & 7,85 & 2,62 \\
\hline Duroia duckei Huber & 20 & 2,31 & 15 & 3,95 & 0,20 & 0,69 & 6,95 & 2,32 \\
\hline Mabea sp. & 20 & 2,31 & 15 & 3,95 & 0,13 & 0,42 & 6,68 & 2,23 \\
\hline Eugenia sp. 1 & 19 & 2,20 & 15 & 3,95 & 0,10 & 0,35 & 6,50 & 2,17 \\
\hline Sapium obovatum Klotzsch ex Müll. Arg. & 14 & 1,62 & 11 & 2,89 & 0,10 & 0,33 & 4,85 & 1,62 \\
\hline Pterocarpus cf. rohrii Vahl & 11 & 1,27 & 10 & 2,63 & 0,10 & 0,34 & 4,24 & 1,41 \\
\hline Coccoloba ochreolata Wedd. & 10 & 1,16 & 8 & 2,11 & 0,01 & 0,04 & 3,30 & 1,10 \\
\hline Mouriri guianensis Aubl. & 5 & 0,58 & 5 & 1,32 & 0,004 & 0,01 & 1,91 & 0,64 \\
\hline Licania parvifolia Huber & 3 & 0,35 & 3 & 0,79 & 0,22 & 0,74 & 1,88 & 0,63 \\
\hline Calophyllum brasiliensis Cambess. & 3 & 0,35 & 3 & 0,79 & 0,13 & 0,44 & 1,58 & 0,53 \\
\hline Dalbergia cf. riedelii (Benth.) Sandwith & 3 & 0,35 & 2 & 0,53 & 0,10 & 0,34 & 1,21 & 0,40 \\
\hline Myrtaceae 2 & 3 & 0,35 & 3 & 0,79 & 0,004 & 0,01 & 1,15 & 0,38 \\
\hline Banara arguta Briq. & 2 & 0,23 & 2 & 0,53 & 0,008 & 0,03 & 0,78 & 0,26 \\
\hline Trichilia claussenii C. DC. & 2 & 0,23 & 2 & 0,53 & 0,004 & 0,01 & 0,77 & 0,26 \\
\hline Alchornea discolor Poepp. & 2 & 0,23 & 2 & 0,53 & 0,001 & 0,004 & 0,76 & 0,25 \\
\hline Rheedia brasiliensis (Mart.) Planch. \& Triana & 2 & 0,23 & 1 & 0,26 & 0,06 & 0,21 & 0,70 & 0,23 \\
\hline Inga uraguensis Hook. \& Arn. & 1 & 0,12 & 1 & 0,26 & 0,005 & 0,02 & 0,40 & 0,13 \\
\hline Cecropia pachystachya Trécul & 1 & 0,12 & 1 & 0,26 & 0,003 & 0,01 & 0,39 & 0,13 \\
\hline Buchenavia oxycarpa (Mart.) Eichler & 1 & 0,12 & 1 & 0,26 & 0,003 & 0,009 & 0,39 & 0,13 \\
\hline Total & 865 & 100 & 380 & 100 & 29,57 & 100 & 300 & 100 \\
\hline
\end{tabular}

na parcela P3 (Tab. 6), fruto da menor eqüabilidade ali encontrada, o que demonstra que muitas espécies ocorreram em baixas densidades. A maior dominância de Vochysia divergens, encontrada nas áreas com maior altura da lâmina de água, resultou em uma menor diversidade do componente lenhoso, assim como visto em outras comunidades monodominantes (Connel \& Lowman 1989, Marimon \& Felfili 2000). A parcela localizada na porção mais alta e seca do gradiente, $\mathrm{P} 1$, obteve um índice de diversidade comparável àquele encontrado num cerrado na cidade de Cuiabá, MT $\left(H^{\prime}=2,60\right)$ (Nascimento \& Saddi 1992), e com valor inferior aos vistos num cerrado, na baixada cuiabana, MT $\left(\mathrm{H}^{\prime}=3,17\right)$ (Oliveira-Filho et al. 1989), num estande de mata atlântica $\left(\mathrm{H}^{\prime}=4,21\right.$ e 4,30) (Moreno et al 2003) e em floresta amazônica $\left(\mathrm{H}^{\prime}=2,91\right.$ a 3,50)
(Ivanauskas et al. 2004).

A diversidade de espécies apresentou relação inversa com a altura da lâmina de água da inundação $\left(\mathrm{R}^{2}=84 \%\right.$ ) (Fig. 5). O mesmo foi verificado por Nascimento \& Nunes da Cunha (1989) num cambarazal no pantanal de Poconé, MT. O alto estresse da inundação parece exercer um papel limitante sobre a vegetação arbórea, selecionando poucas espécies adaptadas a estas condições (Lüttge 1997). A existência de um pequeno número de espécies lenhosas, adaptadas aos mais longos hidroperíodos, pode estar explicando não apenas a menor riqueza de espécies encontradas nas parcelas $\mathrm{P} 2$, $\mathrm{P} 3$ e $\mathrm{P} 4$, mas também o aumento da rique$\mathrm{za}$, na parcela $\mathrm{P} 1$, em que competidoras tornam-se mais abundantes em função da diminuição da freqüência e nível da inundação (Grime 1994). 


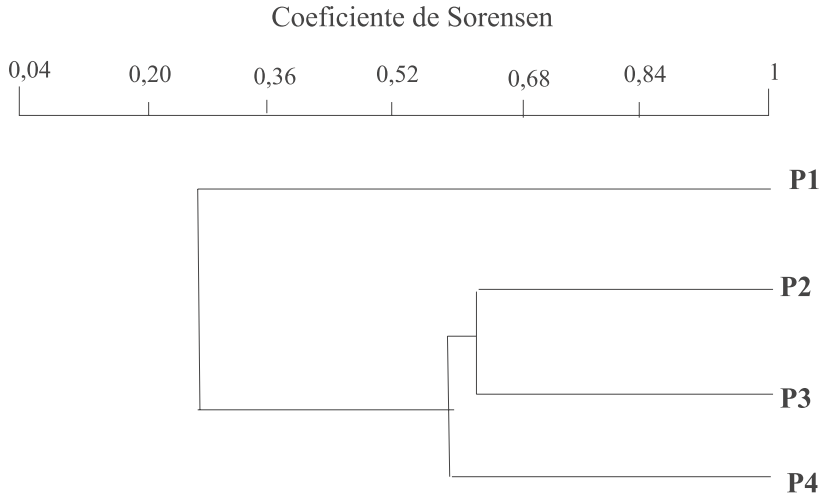

Figura 4. Dendograma de análise de agrupamento por UPGMA, usando índice de similaridade de Sørensen, aplicado à quatro parcelas amostrais (P1, P2, P3 e P4). RPPN SESC Pantanal, Barão de Melgaço, Mato Grosso (Brasil).

A influência da inundação sobre a distribuição de espécies, verificada neste estudo, aponta para a importância deste fator, ora como estressor para comunidades de plantas, ora como promotor de diversidade de habitats e espécies. Esta relação é uma chave importante para a compreensão da dinâmica da vegetação no pantanal. Uma comparação entre duas formações vegetais adjacentes, porém distintas, uma rica e outra pobre em espécies, revela processos que promovem diferenças bruscas em estrutura e composição florística (Hart et al. 1989), como foi verificado na $\mathrm{P} 1$ em relação às demais parcelas amostrais.

Estudos que enfoquem padrões de regeneração florestal, enfatizando a resposta dos indivíduos às flutuações físicas e bióticas do ambiente, poderão ajudar a responder algumas questões sobre a permanência destas florestas monodominantes no pantanal (Duncan 1993). Neste sentido, estudos de longa duração fornecerão conhecimento de maior precisão, para embasar o manejo e a conservação da biodiversidade.

\section{Agradecimentos}

Este trabalho foi desenvolvido sob os auspícios do Programa de Pesquisas Ecológicas de Longa Duração (PELD/CNPq) e é resultado do projeto de dissertação de mestrado de Julia Arieira Couto, aluna do Programa de Pós-graduação do curso de Ecologia e Conservação da Biodiversidade (2003-2005), Universidade Federal de Mato Grosso (UFMT). Agradecemos bolsa de estudos cedida pelo CNPq, o apoio financeiro da The
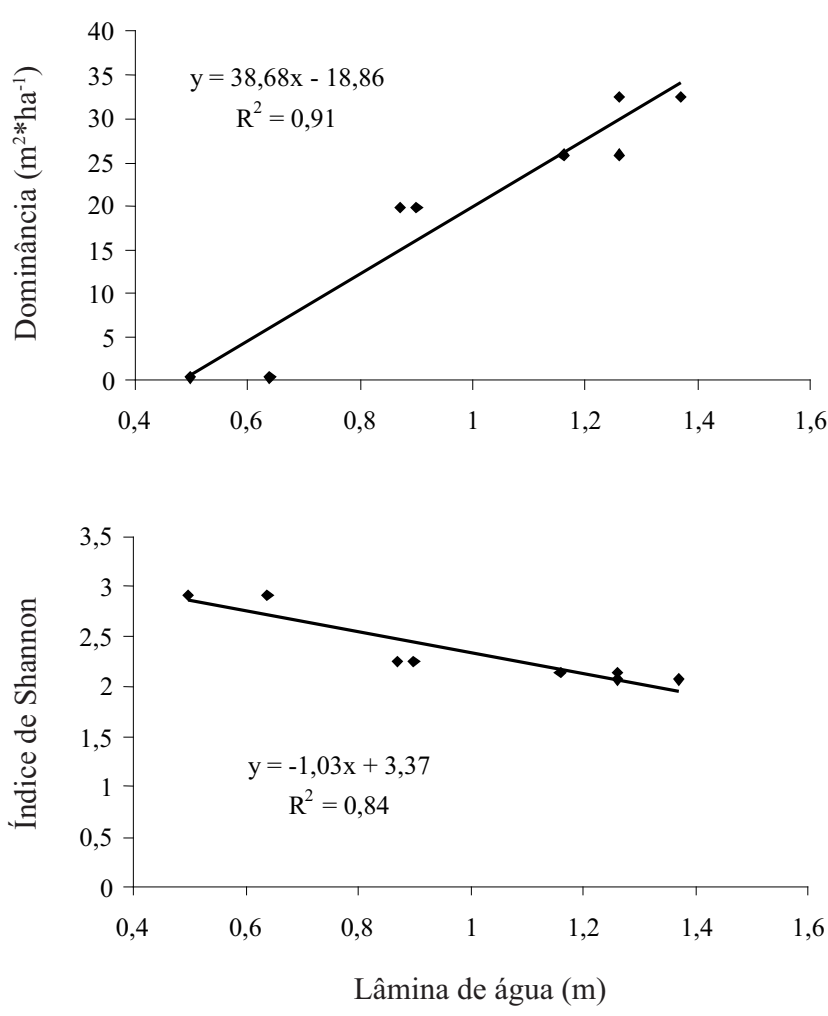

Figura 5. Relações existentes entre a dominância absoluta do cambará $\left(\mathrm{m}^{2 *} \mathrm{ha}^{-1}\right)$ e a diversidade de espécies (índice Shannon) com a altura da lâmina de água $(\mathrm{m})$, no cambarazal. As equações de regressão linear e os coeficientes de determinação $\left(\mathrm{R}^{2}\right)$ são apresentados na figura.

Tabela 6. Índices de diversidade Shannon (H', $\log \mathrm{N}$ ), de eqüabilidade (J') e a riqueza de espécies com DAP $\geq 1,6 \mathrm{~cm}, \geq 10 \mathrm{~cm}$ e $\geq 15$ $\mathrm{cm}$, encontrados nas quatro parcelas amostrais (P1 a P4), na RPPN SESC Pantanal, Barão de Melgaço, Mato Grosso (Brasil). Houve diferença estatística entre os valores médios das parcelas $(\mathrm{P}<0,05)$, para dados de diversidade Shannon e riqueza de espécies. Barão de Melgaço, Mato Grosso (Brasil).

\begin{tabular}{|c|c|c|c|c|c|c|c|c|c|}
\hline \multirow{2}{*}{$\begin{array}{l}\text { Diâmetro } \\
\text { Parcela }\end{array}$} & \multicolumn{3}{|c|}{$\mathrm{H}^{\prime}$} & \multicolumn{3}{|c|}{$\mathrm{J}^{\prime}$} & \multicolumn{3}{|c|}{ Riqueza } \\
\hline & $\geq 1,6 \mathrm{~cm}$ & $\geq 10 \mathrm{~cm}$ & $\geq 15 \mathrm{~cm}$ & $1,6 \mathrm{~cm}$ & $\geq 10 \mathrm{~cm}$ & $\geq 15 \mathrm{~cm}$ & $1,6 \mathrm{~cm}$ & $\geq 10 \mathrm{~cm}$ & $\geq 15 \mathrm{~cm}$ \\
\hline$\overline{\mathrm{P} 1}$ & 2,91 & 2,65 & 2,67 & 0,71 & 0,75 & 0,79 & 59 & 34 & 29 \\
\hline $\mathrm{P} 2$ & 2,25 & 1,28 & 1,05 & 0,76 & 0,58 & 0,51 & 19 & 9 & 8 \\
\hline P3 & 2,07 & 1,21 & 1,10 & 0,60 & 0,44 & 0,43 & 31 & 16 & 13 \\
\hline $\mathrm{P} 4$ & 2,13 & 0,61 & 0,45 & 0,65 & 0,23 & 0,20 & 26 & 14 & 10 \\
\hline
\end{tabular}


Nature Conservancy do Brasil e o apoio logístico do SESC Pantanal, ao desenvolvimento da pesquisa. Enriqueceram este trabalho os comentários e orientações dos pesquisadores: Pierre Girad, Wolfgang J. Junk, Marcelo Trindade Nascimento. Agradecemos: ao Dr. Marcos A. Figueiredo, pela colaboração na elaboração das figuras da área de estudo; aos Dr. Alexandre Francisco da Silva, Dr. Germano Guarim Neto e à Dra. Hélida Bruno, pela colaboração na identificação dos espécimes de plantas; aos esforços nas coletas de dados em campo dos técnicos, Hélio Ferreira e José E. da Silva e de todos os guarda-parques da RPPN SESC Pantanal.

\section{Referências bibliográficas}

Carvalho, N.O. 1986. Hidrologia da Bacia do Alto Paraguai. Pp.43-48. In: Anais do I Simpósio sobre Recursos Naturais e Sócio-econômicos do Pantanal. Brasília, Corumbá, EMBRAPA - CPAP.

Collischonn, W.; Tucci, C.E.M. \& Clarke, R.T. 2001. Further evidence of changes in the hydrological regime of the river Paraguay: part of a wider phenomenon of climate change? Journal of Hydrology 245: 218-238.

Connell, J.H. \& Lowman, M.D. 1989. Low-density tropical rain forests: some possible mechanism for their existence. The American Naturalist 134: 88-119.

Coutinho, L.M. 1990. Fire in the ecology of the Brazilian cerrado. Pp. 82-107. In: J.G. Goldammer (ed.). Fire in the Tropical biota: ecosystem processes and global challenges. Springer-Verlag, Ecological Studies 84: 82-107.

Duncan, R.P. 1993. Flood disturbance and the coexistence of species in a lowland podocarp forest, south Westland, New Zealand. Journal of Ecology 81: 403-416.

Faßnacht, N.J.M. 1995 Vegetationskartierung mit Hilfe von Landsat-TM-Daten zur Abgrenzung der Baurmart Vochysia divergens im Pantanal, Mato-Grosso - Brasilien. Diplomarbeit der Forstwessenschaftlinchen Fakultät der Ludwig - Maximilians - Universität München.

Fonseca, M.S. \& Silva Junior, M.C. 2004. Fitossociologia e similaridade florística entre trechos de cerrado sentido restrito em interflúvio e em vale no Jardim Botânico de Brasília, DF. Acta Botanica Brasilica 18(1): 19-29.

Gotelli, N.J. \& Ellison, A.M. 2004. A Primer of Ecological Statistics. Sunderland, Massachusetts, Sinauer Associates.

Grime, J.P. 1994. The role of plasticity in exploiting environmental heterogeneity: ecophysiological processes above- and belowground, Cap. 1. Pp. 2-16. In: M. Caldwell \& R.W. Pearcy (eds.). Exploitation of environmental heterogeneity by plants. Academic Press.

Guarim Neto, G.; Guarim, V.L.M. \& Prance, G.T. 1994. Structure and floristic composition of the trees of an area of cerrado near Cuiabá, Mato Grosso, Brazil. Kew Bulletin 49(3): 499-509.

Hamilton, S.K.; Sippel, S.J. \& Melack, J.M. 1996. Inundation patterns in the Pantanal wetland of South America determined from passive microwave remote sensing. Archiv für Hydrobiologie 137(1): 1-23.
Hart, T.B.; Hart, J.A. \& Murphy, P.G. 1989. Monodominant and species-rich forests of the humid tropics: causes for their co-occurrence. The American Naturalist 133(5): 613-633.

Hart, T.B. 1990. Monospecific dominance in Tropical Rain Forests. Tree 5(1): 6-11.

Hasenack, H.; Cordeiro, J.L.P. \& Hofmann, G.S. 2003. O clima da RPPN SESC Pantanal. Porto Alegre, UFRGS.

Ikeda-Castrillon, S.; Mesquita, R.; Sanaiotti, T.; Frieiro, F. \& Castrillon, J.R. 2001. Localização e dominância de espécies das ilhas de vegetação arbórea ao longo do rio Paraguai no Pantanal de Cáceres, MT. 11 p. In: Anais do III Simpósio sobre Recursos Naturais e Sócio-Econômicos do Pantanal - os desafios do novo milênio. Corumbá - MS, 2000. Brasília, Embrapa - CPAP.

Isaacs, R.; Gillman, M.P.; Johnston, M.; Marsh, F. \& Wood, B.C. 1996. Size structure of a dominant Neotropical forest tree species, Dicymbe altsonii, in Guyana and factors reducing seedling leaf area. Journal of Tropical Ecology 12: 599-606.

Ivanauskas, N.M.; Monteiro, R. \& Rodrigues, R.R. 2004. Estrutura de um trecho de floresta amazônica na bacia do alto Xingu, Acta Amazonica 34(2): 275-299.

Junk, W.J.; Bayley, P.B. \& Sparks, R.E. 1989. The flood pulse concept in river - floodplain systems. Pp. 110-127. In: D.P. Dodge (ed.). Proceedings International Large River Symposium (LARS), Can Sepc. Publ. Fish Aquat. Sci. 106: $110-127$.

Junk, W.J. \& Da Silva, C.J. 1999. O Conceito de Pulso de Inundação e suas implicações para o Pantanal de Mato Grosso. Pp.17-28. In: Anais do II Simpósio sobre Recursos Naturais e Sócio-Econômicos do Pantanal: Manejo e Conservação. Corumbá - MS, 1996. Brasília, Embrapa - CPAP.

Junk, W.J. 2002. Long-term environmental trends and future of tropical wetlands. Environmental Conservation, Foundation for Environmental Conservation 29(4): 414-435.

Kent, M. \& Coker, P. 1994. Vegetation description and analysis. A Practical Aprroach. Chichester, UK. John Willey.

Keogh, Teri M.; Keddy, P.A. \& Fraser, L.H. 1999. Patterns of tree species richness in forested wetlands. Wetlands 19(3): 639-647.

Köppen, W. 1948. Climatologia. México, Buenos Aires, Ed. Fundo de Cultura Econômica.

Kovack, W.L. 1993. MVSP (Multivariate Statistical Package). Kovack PLC.

Lugo, A.E. 1990. Ecosystems of the World 15: Forested Wetlands. Ariel E. Lugo, M. Brinson \& S. Brown (eds.).

Lüttge, U. 1997. Physiological Ecology of Tropical Plants. Germany, Springer-Verlag Berlin Heidelberg.

Magurran, A.E. 1988. Diversidad Ecológica y su Medición. Espanha, Vedrà.

Marimon, B.S. \& Felfili, J.M. 2000. Distribuição de diâmetros e alturas na floresta monodominante de Brosimum rubescens Taub. na Reserva Indígena Areões, Água Boa-MT, Brasil. Viçosa - MG. Revista Árvore 24(2): 143-150.

Moreno, M.R.; Nascimento, M.T. \& Kurtz, B.C. 2003. Estrutura e composição florística do estrato arbóreo em duas zonas altitudinais na Mata Atlântica de encosta da região do Imbê, RJ. Acta Botanica Brasilica 17(3): 371-386. 
Mueller-Dombois, D. \& Ellemberg, H. 1974. Aims and Methods of Vegetation Ecology. New York, John Wiley \& Sons.

Nascimento, M.T. \& José, D.V. 1986. O cambarazal no Pantanal de Mato Grosso. Boletim FBCN 21: 116-123.

Nascimento, M.T. \& Nunes da Cunha, C. 1989. Estrutura e composição florística de um cambarazal no Pantanal de Poconé - MT. Acta Botanica Brasilica 3(1): 3-11.

Nascimento, M.T. \& Saddi, N. 1992. Structure and floristic composition in an area of cerrado in Cuiabá-MT, Brazil . Revista Brasileira de Botânica 15(1): 47-55.

Nascimento, M.T. \& Proctor, J. 1997. Soil and plant changes across a monodominant rain forest boundary on Maracá island, Roraima, Brazil. Global Ecology and Biogeography Letters 6(5): 387-395.

Nunes da Cunha, C. \& Junk, W.J. 1999. Composição florística de capões e cordilheiras: localização das espécies lenhosas quanto ao gradiente de inundação no Pantanal de Poconé, MT, Brasil. Pp.387-406. In: Anais do II Simpósio sobre Recursos Naturais e Sócio-Econômicos do Pantanal - manejo e conservação. Corumbá, MS, 1996. Embrapa - CPAP.

Nunes da Cunha, C; Junk, W.J.; Falessa, O.; Costa, C.P. \& Almeida, L. 2000. Influences of dry and flooding periods on phenology and the dynamic of seedlings and saplings of Vochysia divergens Pohl, in the Pantanal of Poconé. Pp. 871-874. In: German-Brazilian Workshop on Neotropical Ecosystems - Achievements and Prospects of Cooperative Research. Hamburg.

Nunes da Cunha, C. \& Junk, W.J. 2001. Distribution of wood plant communities along the flood gradient in the Pantanal of Poconé, Mato Grosso, Brazil. International Journal of Ecology and Environmental 27: 63-70.

Nunes da Cunha, C. \& Oliveira, E.V.R. 2001. Influência da seca na dinâmica de população de indivíduos juvenis de Vochysia divergens Pohl Fazenda Retiro Novo - Pantanal de Poconé, MT. 12 p. In: Anais do III Simpósio sobre Recursos Naturais e Sócio-Econômicos do Pantanal - os desafios do novo milênio. Corumbá, 2000. Brasília, Embrapa - CPAP.

Nunes da Cunha, C. \& Junk, W.J. 2004. Year-to-year changes in water level drive the invasion of Vochysia divergens in Pantanal grasslands. Applied Vegetation Science 7: 103-110.

Oliveira Filho, A.T.; Shepherd, G.J.; Martins, F.R. \& Stubblebine, W.H. 1989. Environmental factors affecting physiognomic and floristic variation in an area of cerrado in central Brazil. Journal of Tropical Ecology 5: 413-431.

Parolin, P.; Oliveira, A.C.; Piedade, M.T.F.; Wittmann, F. \& Junk, W.J. 2002. Pioneer trees in Amazonian floodplains: three key species form monospecific stand in different habitats. Folia Geobotânica 37: 225-238.

PCBAP- Plano de Conservação da Bacia do Alto Paraguai
(Pantanal) 1997. Diagnóstico dos meios físicos e bióticos. Ministério do Meio Ambiente, dos Recursos Hídricos e da Amazônia Legal, v.2, tomo 3.

Pott, A. \& Pott, V.J. 1994. Plantas do Pantanal. Corumbá, Embrapa - CPAP.

Prance, G. \& Schaller, G.B. 1982. Preliminary study of some vegetation types of the Pantanal, Mato Grosso, Brazil. Brittonia 34(2): 228-251.

RadamBrasil 1982. Levantamento de Recursos Naturais: 27, Folha SE. 21, Corumbá. Rio de Janeiro, RJ. 452 p. Il.

Richards, M.A. 1957. The Tropical Rain Forest: an Ecological Study. Cambridge, Cambridge at the University Press.

Silva, M.P.; Mauro, R.; Mourão, G.E. \& Coutinho, M. 2000. Distribuição e quantificação de classes de vegetação do Pantanal através de levantamento aéreo. Revista Brasileira de Botânica 23(2): 143-152.

Sørensen, T.A. 1948. Method of establishing groups of equal amplitude in plant sociology based on similarity of species content and its application to analyses of the vegetation on Danish commons K. Dansk. Vidensk. Selsk. Biol. Skrift, The Royal Danish Academy of Sciences and Letters 5(4): 3-16, 34.

Stafleu, F.A. 1948. A monograph of the Vochysiaceae. I. Salvertia and Vochysia. Recueil des Travaux Botaniques Néerlandais 41: 398-540.

Van Der Valk, A.G. 1981. Succession in wetlands: a Gleasonian approach. Ecology 62(3): 689-696.

Veloso, H.P. 1972. Aspectos fitoecológicos da Bacia do Alto Paraguai. Biogeografica 7: 1-31. 